\title{
Baixada Fluminense como vazio demográfico? População e território no antigo município de Iguaçu (1890/1910)
}

\author{
Lúcia Silva*
}

O município de Iguaçu ocupava o que atualmente é denominado de Baixada Fluminense, englobando o que hoje são os municípios de Belford Roxo, Duque de Caxias, Japeri, Mesquita, Nilópolis, Nova Iguaçu, Queimados e São João de Meriti, com um território que representava $35 \%$ da atual região metropolitana do Rio de Janeiro. A noção de Baixada Fluminense unifica o que as emancipações fragmentaram, já que a região no final do século XIX era um município com atividades rurais e, ao longo do século XX, transformou-se em periferia urbana. Chama a atenção a afirmação recorrente dos pesquisadores que estudam a região acerca da existência de um vazio demográfico que teria ocorrido no final do século XIX (1890/1910). 0 objetivo deste texto é apresentar os principais argumentos utilizados na construção da imagem de vazio demográfico e, com base nos dados obtidos nos censos, oferecer alguns elementos que questionam essa leitura na forma como é enunciada, pois a principal tese é a de que a região da Baixada (como um todo) ficou despovoada e, com as terras vazias, foi ocupada desordenadamente por uma população urbana fugindo dos altos preços da capital federal. Esta leitura recorrente obscurece outras dinâmicas existentes no território, além da própria história da região.

Palavras-chave: Baixada Fluminense. População. Ocupação. História.

\footnotetext{
* Universidade Federal Rural do Rio de Janeiro (UFRRJ), Nova Iguaçu-RJ, Brasil (luciahelena.silva@pq.cnpq.br).
} 


\section{Introdução}

No período abordado por este texto, o município de Iguaçu ocupava o que atualmente é denominado de Baixada Fluminense, isto é, tinha sob sua jurisdição as municipalidades de Belford Roxo, Duque de Caxias, Japeri, Mesquita, Nilópolis, Nova Iguaçu, Queimados e São João de Meriti, abrangendo um território que representava $35 \%$ da atual região metropolitana do Rio de Janeiro. A noção de Baixada Fluminense ${ }^{1}$ unifica o que as emancipações fragmentaram, já que a região no final do século XIX era um município rural e, ao longo do século XX, transformou-se em periferia urbana. Contar a história desse processo, principalmente no que tange à sua ocupação, permite entender essa transformação.

Ainda que a dinâmica populacional não seja o objeto privilegiado da pesquisa, chama a atenção a afirmação recorrente dos pesquisadores que estudam a região acerca da existência de um vazio demográfico ocorrido no final do século XIX (1890/1910). Essa afirmação aparece não só nos memorialistas do início do século XX descritos por Marques (2005), como também nos novos pesquisadores que se debruçam sobre a história da Baixada Fluminense.

Assim, o objetivo deste texto é apresentar os principais argumentos utilizados na construção da imagem do vazio demográfico e, com base nos dados obtidos nos censos, oferecer alguns elementos que questionam essa leitura na forma como é enunciada, pois a principal tese é a de que a Baixada ficou despovoada, entre 1890 e 1910, e com as terras vazias pode ser ocupada urbanamente. Para dar conta desta proposta é necessário contar a história do lugar, valorizando a dinâmica populacional da região no período e fazer uma breve discussão acerca desse vazio. Buscando cumprir tais objetivos, o texto está dividido em duas partes, uma que discorre sobre o processo de ocupação e outra que apresenta uma interpretação para o vazio demográfico.

Entretanto, duas observações devem ser feitas. A primeira é que a narrativa aqui tem preocupações com a demografia, mas não é um texto de demografia histórica, na medida em que se privilegia a imagem construída do processo de declínio populacional, e não a análise do processo em si, não sendo, portanto, um estudo da população, nem da história da população. Pode-se dizer que se trata da explicitação de uma inquietação acerca de uma lacuna nesta desconhecida história da população. Dessa forma, as informações contidas nos censos serão vistas, a priori, como dados da realidade, sem discussão metodológica de como foram constituídas, prática corrente da demografia histórica. A segunda observação é sobre o território pesquisado, já que Baixada Fluminense é aqui entendida como um conceito que serve para designar uma região que compreendia as terras pertencentes do antigo município de Iguaçu no início do século XX.

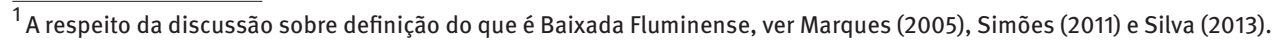




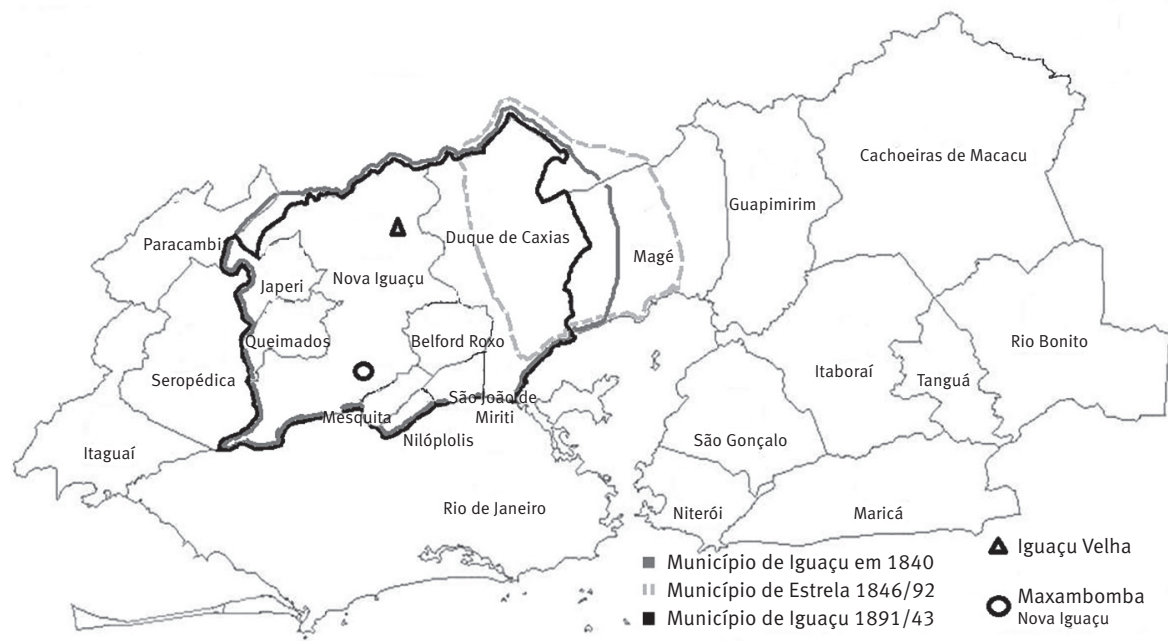

Fonte: Elaboração da autora a partir de Oliveira Junior (1926, p.149 e segs.).

\section{Um pouco de história da Baixada Fluminense}

Baixada foi um termo cunhado no final do século XIX para designar a porção de terra do lado oeste da baia da Guanabara. Conhecida como Arrabalde ou Grande Iguaçu, a região foi ocupada ainda no século XVI pelas fazendas de cana-de-açúcar. Essa formação social, assentada na existência da grande fazenda ou engenho com mão de obra escrava, passou a conviver com a dinâmica econômica voltada à logística de escoamento de produtos vindo do interior quando descoberto o ouro, no século XVIII, e depois com a produção do café, no século XIX.

Ao longo do século XIX, a região de uma maneira geral conviveria com duas dinâmicas econômicas: a área mais próxima da baia de Guanabara especializou-se no escoamento dos produtos vindo do interior por meio de seus rios e portos, enquanto a mais distante tinha como base as lavouras de café e mandioca, substituindo a cana. Essas duas realidades na mesma região foram alteradas com a construção da ferrovia D Pedro II (Central do Brasil), em 1856.

A passagem da via férrea, ao mesmo tempo que inseriu a região no rol das atenções do Estado Imperial, levou à decadência da estrutura de escoamento calcada nos rios e portos da área mais próxima à baia. É a partir deste momento que os autores começam a discorrer sobre um possível vazio demográfico da região.

No último quartel do século XIX, o município era uma grande região com muitas freguesias. A antiga e pujante Villa de Iguaçu, às margens do rio do mesmo nome, entrou em decadência, enquanto a área mais distante da baia, Maxambomba (atual cidade de Nova 
Iguaçu), passou a escoar toda a produção local por meio de sua estação de trem. A população do município, segundo o censo de 1872, era de 19.971 habitantes, mas se contar com Pilar, naquele momento pertencente ao município de Estrela, a região contaria com 23.381 habitantes - essa freguesia voltou a pertencer a Iguaçu² na República.

Nesse período, a freguesia mais populosa do município criado em 1833 era a de Jacutinga, onde se localizava Maxambomba; Iguaçu Velha, sede municipal, já entrara em processo de decadência. Em 1872 Iguaçu tinha uma área 1.305,47 km² (ALMANAK ADMINISTRATIVO, MERCANTIL E INDUSTRIAL, 1880, p. 114), aumentando com o retorno de Pilar em 1892, passando para 1.527,67 km² (ALMANAK LAEMMERT, 1913, p. 4866). Segundo Pereira (1970), foram 23 anos de crises intermitentes em que se alternaram as epidemias de cólera e de varíola, sendo esta última "o derradeiro golpe" que possibilitou a transferência da sede de Iguaçu para Maxambomba, já na República.

Resumindo: o município foi criado em 1833, mas, com a emancipação de Estrela em 1846, parte de seu território foi desmembrado, voltando a tê-lo na República; de município próspero com duas grandes atividades econômicas, a agricultura e a logística do escoamento do café entraram em decadência depois de 1870, em função da construção da linha férrea e das diversas doenças que assolaram a região. Pereira (1970) é um dos autores a descrever a crise sanitária que transformou a vila de Iguaçu em "cidade fantasma”, utilizando outro autor (FORTE, 1933) como referência, que, por sua vez, citou as memórias de Rodrigo Octavio, publicadas pela primeira vez em 1928.

Pouco tempo depois de minha chegada à antiga Corte, fui mandado para Iguassu como juiz municipal.

A poucas horas da Ponta do Caju, pela estradinha do Rio Douro, a Vila de Iguassu era então um grande povoado morto. [...] Ligada com o interior da baia de Guanabara por canais através da alagadiça baixada fluminense Iguassu fora, por muito tempo, o entreposto comercial entre o litoral e o sertão. (OCTAVIO apud FORTE, 1933, p. 65)

A imagem da decadência econômica, juntamente com as diversas epidemias, promoveu a emigração, acabando por deixar a região vazia. Essa leitura foi também corroborada por outros pesquisadores, como a geógrafa Soares (1962), cuja interpretação sobre o processo de ocupação da região é consagrada, difundida entre os novos pesquisadores. Segundo a autora:

O fim do século iria, porém, assistir a uma profunda modificação nessas relações, decorrentes do estabelecimento das ligações ferroviárias com o interior e do crescente desinteresse da metrópole pela baixada que, abandonada aos próprios e parcos recursos e privada, pela abolição da escravidão, da mão-de-obra que lhe permitia, ainda, subsistir como zona agrícola, iria entrar numa decadência profunda. Aos poucos, o brejo e a malária tomaram conta daquela região, que, durante dois séculos, estivera tão ligada à cidade. 0 mato invadiu as estradas, os rios e canais entupiram-se com a falta de limpeza e de dragagem, as populações fugiram. (SOARES, 1962, p. 24, grifo nosso)

\footnotetext{
${ }^{2}$ As informações sobre as divisões político-administrativas do município de Iguaçu e de Estrela foram extraídas da legislação sobre municípios, comarcas e distritos de Oliveira Junior (1926).
} 
Esta interpretação é compartilhada em parte por Simões (2007), ao utilizar o argumento do vazio para explicar as mudanças que ocorreriam no espaço rural que levaram o município de São João de Meriti a ser ocupado urbanamente no início do século XX. Tal entendimento também é encontrado em Braz e Almeida (2010) ao analisarem o mesmo processo em Duque de Caxias.

Em 1910, Merity, o quarto distrito de Nova Iguaçu, contava com uma população de pouco mais de 800 habitantes, número assustadoramente baixo se comparado aos 10.542 auferidos em 1872 pelo censo estadual. Essa queda populacional vertiginosa era conseqüência direta de problemas que assolava a região desde meados do século XIX, da crise econômica e ecológica que atingiram de forma muito dura, principalmente essas empobrecidas, baixas e pantanosas terras próximas a baia de Guanabara. (BRAZ; ALMEIDA, 2010, p. 35, grifo nosso)

A ideia de que a população declinou a um número "assustadoramente baixo", deixando a região vazia, é utilizada para descrever em cores fortes esse vazio demográfico. Tal declínio não só prejudicou as atividades agrícolas desenvolvidas na Baixada, mas também permitiu que as terras fossem ocupadas urbanamente, ainda que sem estrutura urbana, pela população vinda da cidade do Rio de Janeiro, seguindo as linhas férreas. Dessa forma, a região era descrita como lugar da malária e do impaludismo, sertão a ser civilizado por meio do saneamento. Vazia, poderia ser ocupada por novos personagens.

\section{Interpretações sobre o vazio demográfico da Baixada Fluminense}

Ocupando um território de aproximadamente 1.500 km², em 1840, o município de Iguaçu possuía 15.049 habitantes. Em 1872, nessa mesma área residiam 23.381 pessoas (incluindo a freguesia que passou a Estrela em 1846), sendo que essa população diminuiu para 22.229 habitantes, em 1890, e chegou a 33.963 pessoas, em 1920. De fato, entre 1872 e 1890 houve um decréscimo da população, o que ocorreu em quase todas as freguesias, com exceção de Santana das Palmeiras e São João de Meriti. É importante ressaltar que Palmeira foi uma freguesia criada em 1856 por meio do desmembramento de Piedade de Iguaçu, onde se localizava a sede municipal.

As freguesias foram posteriormente transformadas em distritos e tiveram seus territórios desmembrados ao longo do tempo; por isso, busca-se a referência no espaço ocupado por elas e não na estrutura político-administrativa do município. A passagem do Império para a República e a ocupação urbana nas franjas do Rio de Janeiro fragmentaram os distritos do grande município e, com o processo de urbanização (sem estrutura urbana) acentuado depois de 1920, quase todos os distritos tornaram novos municípios após 1940.

Além dos problemas apontados pelos pesquisadores que se debruçam sobre o estudo da população no século XIX em relação à obtenção dos dados demográficos, no caso de Iguaçu ainda há a criação do município de Estrela em 1846, dificultando estabelecer espacialmente qual era o território descrito como vazio demográfico. As informações colhidas, 
embora não correspondam exatamente à região estudada, por conta dos limites dos municípios, não deixam de ser indícios da dinâmica populacional ocorrida no período na região. Entre 1846 e 1892, o município de Iguaçu dividiu com Estrela as terras da Baixada Fluminense e essa região, ao longo do último quartel do século XIX, em áreas diferentes, perdeu população, mas isso seria o suficiente para corroborar com o vazio?

A emancipação de Estrela ocorreu em função do seu ativo porto e sua extinção, com o advento da República, aconteceu porque a ferrovia já concentrava todo escoamento do café. O declínio de Estrela foi similar ao caso da vila de Iguaçu, inclusive os mesmos argumentos poderiam explicar porque as freguesias de Pilar e Piedade de Iguaçu (Cava) tiveram redução de sua população no período 1872-1890. Se a dinâmica demográfica de uma região está intimamente ligada com sua estrutura produtiva (MADEIRA; TORRES, 1996), Jacutinga (onde se localizava Maxambomba, que mudaria de nome em 1916 para Nova Iguaçu), que começava a desenvolver a lavoura da laranja, sendo, portanto, a freguesia com maior crescimento econômico do município, deveria ter aumentado sua população, mas isso não ocorreu.

Os estudiosos da região descrevem a última década do século XIX como o período em que a Baixada teria ficado despovoada. As causas do despovoamento seriam as doenças, o aumento das áreas alagadiças e o declínio das atividades econômicas, que teriam levado a população a emigrar. A região só voltaria a ser ocupada na segunda década do século XX.

Os dados colhidos mostram que a região sempre fora pouco ocupada, mesmo quando não era vista como vazio. Em 1840, quando o município era considerado próspero, sua população correspondia a 15.049 habitantes, enquanto Campos, o município mais populoso da província na mesma época, abrigava 64.732 pessoas e Niterói, a capital da província, tinha 25.415 habitantes. Os demais municípios do Rio de Janeiro possuíam populações similares à de Iguaçu, mesmo no Vale do Paraíba, centro dinâmico da economia cafeeira, cujos municípios de Pirai, Vassouras e Valença tinham, respectivamente, 12.101, 17.232 e 20.589 habitantes em 1840 .

Com densidade demográfica de 9,85 , hab. $/ \mathrm{km}^{2}$ em 1840 , no período considerado como vazio (1890-1910), o município passou a registrar 14,55 hab. $/ \mathrm{km}^{2}$, em 1890, e 21,01 hab. $/ \mathrm{km}^{2}$, em 1910. Nesse espaço de tempo, a população cresceu 31,32\% e o município passou a contar com 32.105 habitantes (BRAZIL, 1916, p. 340), chegando a 22,23 hab./km², em 1920.

Ainda que se desconsidere a correspondência espacial população/território e se utilize somente a divisão político-administrativa, ou seja, apenas o município com denominação de Iguaçu, observa-se que o mesmo processo ocorreu, já que a unidade tinha uma população de 15.049 pessoas, em 1840, passando para 19.971, em 1872, diminuindo para 19.712, em 1890, para apenas 18.629 habitantes, em 1900 (BRAZIL, 1905), e chegando a 32.105 em 1910 (BRAZIL, 1916) e 33.396 habitantes em 1920 (BRAZIL, 1926).

Dessa forma, à primeira vista pode-se afirmar que entre 1872 e 1900 houve de fato um pequeno declínio populacional, visto que cinco das sete freguesias que comporiam o território da Baixada tiveram redução de sua população, ocorrendo em seguida grande crescimento, entre 1900 e 1910 . A mudança de sede estaria dentro período de maior perda, 
como aponta a historiografia, entretanto, mesmo no período de declínio, esse ocorreu de forma desigual, já que em duas freguesias houve aumento populacional. A primeira localizava-se na franja da cidade do Rio de Janeiro e a segunda na franja de Vassouras, já subindo a Serra do Mar, ambas eram estações da Linha auxiliar no início do século XX.

Lembrando que não foram encontrados os dados por distrito nos "censos" de 1900 e 1910, no período considerado como o de vazio (1890-1910), não se pode afirmar como ocorreu o declínio, mas, com base nos censos de 1890 e 1920, as principais perdas estariam nos distritos de Queimados, Cava e Santa Branca, sendo que os demais tiveram crescimento, inclusive superior $100 \%$ (como é o caso de Jacutinga). A antiga Piedade de Iguaçu (Cava) teve sua população reduzida pela metade, da mesma forma que Palmeira. Neste sentido, a historiografia pode ser ratificada apenas para essas duas localidades.

\section{Conclusões preliminares}

A primeira conclusão é que o declínio populacional começou no período anterior ao descrito pela historiografia, ou seja, a partir de 1872 ou até antes. A interpretação para esta diminuição pode estar na construção da estrada de ferro, que deslocou o eixo econômico das "terras alagadas para as terras firmes" (SILVA, 2016), desarticulando a estrutura produtiva local, além das epidemias (que precisam ser investigadas). A segunda conclusão é que a diminuição da população no município não ocorreu de maneira uniforme em todo o território, como mostra a Tabela 1.

TABELA 1

População do território da Grande Iguaçu, segundo freguesias/distritos - 1779-1940

\begin{tabular}{|c|c|c|c|c|c|c|c|c|c|}
\hline $\begin{array}{c}\text { Freguesia } \\
\text { Base } \\
\text { Pizarro } \\
1822\end{array}$ & 1779 & 1821 & 1840 & 1872 & 1890 & 1900 & 1910 & 1920 & 1940 \\
\hline $\begin{array}{l}\text { Piedade } \\
\text { de Iguassu }\end{array}$ & 9.882 & 4.167 & - & 4.485 & 3.576 & - & - & $\begin{array}{l}2.001 \\
\text { (Cava) }\end{array}$ & $\begin{array}{r}3.048 \\
\text { (Cava) }\end{array}$ \\
\hline Jacutinga & 3.540 & 3.700 & 6.061 & 6.546 & 6.567 & - & - & $\begin{array}{r}12.382 \\
(\text { N. Iguassu })\end{array}$ & $\begin{array}{r}34.680+7.434 \\
\text { (N. Iguassu } \\
+ \text { +Belford Roxo) }\end{array}$ \\
\hline Marapicu & 1.821 & 4.202 & 6.586 & 4.999 & 4.456 & - & & $\begin{array}{r}3.063 \\
\text { (Queimados) }\end{array}$ & $\begin{array}{r}3.974 \\
\text { (Queimados) }\end{array}$ \\
\hline $\begin{array}{l}\text { São João } \\
\text { de Meriti }\end{array}$ & 1.616 & 2.264 & 2.402 & 2.323 & 2.970 & - & & $\begin{array}{r}8.255+3.611 \\
\text { (Pavuna+ } \\
\text { S. Matheus) }\end{array}$ & $\begin{array}{r}\text { 39.569+22.341 } \\
\text { (Meriti+ } \\
\text { Nilópolis) }\end{array}$ \\
\hline Palmeiras & * & * & * & 1.618 & 2.143 & - & & $\begin{array}{r}1.261 \\
\text { (Sta. Branca) }\end{array}$ & $\begin{array}{r}1.232 \\
\text { (Bonfim) }\end{array}$ \\
\hline Total & & & & 19.971 & 19.712 & - & - & & \\
\hline $\begin{array}{l}\text { Pilar de } \\
\text { Iguassu }\end{array}$ & 3.895 & 4.372 & & $\begin{array}{c}3.410 \\
\text { (Pertencente }(P \\
\text { à Estrela) }\end{array}$ & $\begin{array}{r}2.517 \\
\text { Pertencente } \\
\text { à Estrela) }\end{array}$ & - & - & 2.823 & $\begin{array}{r}24.711+3.617 \\
\text { (Caxias+Estrela) }\end{array}$ \\
\hline Total & 20.054 & 18.705 & 15.049 & 23.381 & 22.229 & 18.629 & 32.105 & 33.963 & 140.606 \\
\hline
\end{tabular}

Fonte: Revista do Instituto Histórico e Geográfico Brasileiro (1884, 1870), Rio de Janeiro (1851), Brasil (1874, 1898, 1905, 1916, 1926, 1951).

Nota: - sem informação; * não existia a freguesia e seu território fazia parte de Piedade de Iguassu.

Os nomes entre parênteses correspondem às novas denominações do território, distritos. 
Sem pesquisas sobre a região é difícil determinar que fatores fizeram, de fato, a população diminuir, contudo, novos estudos têm indicado que a explosão populacional que ocorreria depois do "vazio", em função da ocupação urbana desordenada, obscureceria processos locais, com dinâmicas diferentes daquelas comandadas pela migração (pendular) da população da cidade do Rio e Janeiro.

Nesse sentido, a agenda de pesquisa será encaminhada em duas direções. A primeira concentrar-se-á no levantamento dos livros de óbitos e batismos existentes no Arquivo da Cúria de Nova Iguaçu, com o objetivo examinar de forma qualitativa/quantitativa o movimento populacional das freguesias do município. A segunda fixar-se-á na análise do período seguinte, principalmente porque tem mais fontes de dados disponíveis, buscando ressaltar as características do crescimento natural, articulando-o aos impactos da (i)migração. Em ambas, pretende-se conhecer mais detalhadamente a dinâmica evolutiva da população local, ressaltando o papel dos nascimentos, mortes e migrações.

A Baixada Fluminense, ainda município de Iguaçu, apesar de próxima à cidade do Rio de Janeiro, e exatamente por isso, é pouco estudada e a história da região, com muitas lacunas, é desconhecida. Esta nota de pesquisa visa, antes de tudo, instigar novos pesquisadores a estudá-la e, principalmente, incentivar novos caminhos para futuras pesquisas acerca do comportamento demográfico de uma população cuja história ainda é desconhecida.

\section{Referências}

ALMANAK ADMINISTRATIVO, MERCANTIL E INDUSTRIAL da corte e província do Rio de Janeiro para o ano de 1880. Rio de Janeiro: Typ. Eduardo e Henrique Laemmert, 1880. Disponível em: 〈http://brazil.crl.edu/bsd/bsd/almanak/al1880/00000002.html〉. Acesso em: 21 mar. 2017.

ALMANAK LAEMMERT 69ํano. Rio de Janeiro: Typ. do Almanak Laemmert, 1913. Disponível em: 〈http://memoria.bn.br/DocReader/docreader.aspx?bib=313394\&pasta=ano\%20191\&pesq=>. Acesso em: 21 mar. 2017.

BRAZIL. Recenseamento do Brazil em 1872. Rio de Janeiro: Typ.G. Leuzinger, v. 10, 1874. Disponível em: 〈http://biblioteca.ibge.gov.br/visualizacao/livros/liv25477_v10_rj.pdf〉. Acesso em: 21 mar. 2017.

Ministério da Indústria, Viação e Obras Públicas. Diretoria Geral de Estatística. Synopse do recenseamento de 1890. Rio de Janeiro: Officina da Estatística, 1898. Disponível em: 〈http://www2.senado.leg.br/bdsf/handle/id/4/browse?value=Censo+demogr\%C3\%A1fic o+Brasil\%2C+(1890).\&type=subject . Acesso em: 19 jun. 2015.

Ministério da Indústria, Viação e Obras Públicas. Diretoria Geral de Estatística. Synopse do recenseamento de 1900. Rio de Janeiro: Officina da Estatística, 1905. Disponível em: 〈http://www2.senado.leg.br/bdsf/handle/id/4/browse?type=subject\&value=Censo+dem ogr\%C3\%A1fico\%2C+Brasil\%2C+1900〉. Acesso em: 19 jun. 2015

. Ministério da Agricultura, Indústria e Commercio. Directoria Geral de Estatística. Anuário Estatístico do Brazil, vol. I, população. Rio de Janeiro: Typ de Estatística, 1916.

Ministério da Agricultura, Indústria e Commercio. Directoria Geral de Estatística Recenseamento do Brazil de 1920. Rio de Janeiro: Typ.da Estatística, 1926. 
BRAZ, A. A.; ALMEIDA, T. A. De Merity a Duque de Caxias: encontro com a história da cidade. Duque de Caxias: Ed. APPH-CLIO, 2010.

BARCELAR, C. A. P.; SCOTT, A. S. V.; BASSANEZI, M. S. C. B. Quarenta anos de demografia histórica. Revista Brasileira de Estudos de População, São Paulo, v. 22, n. 2, 2005.

FORTE, J. M. M. Memórias da fundação de Iguassu. Rio de Janeiro: Typ do Jornal do Comercio, 1933.

IBGE - Instituto Brasileiro de Geografia e Estatística. Censo Demográfico 1940. Rio de Janeiro: IBGE, 1951.

MACHADO, R. Foucault: ciência e saber. 3. ed. Rio de Janeiro: Jorge Zahar ed., 2006.

MADEIRA, F.; TORRES, H. G. População e reestruturação produtiva: novos elementos para projeções demográficas. São Paulo em Perspectiva, São Paulo, v. 10, n. 2, 1996.

MEMÓRIAS públicas e econômicas da cidade de São Sebastião do Rio de Janeiro para o uso do Vice-rei Luiz de Vasconcellos por observação curiosa dos anos de 1779 até 1789. Revista do Instituto Histórico e Geográfico Brasileiro, Rio de Janeiro, v. 47, 1884.

MAPPA da população da corte e da província do Rio de Janeiro em 1821. Revista do Instituto Histórico Geográfico Brasileiro, Rio de Janeiro, v. 33, 1870.

MARQUES, A. dos S. Baixada Fluminense: da conceituação as problemáticas sociais contemporâneas. Revista Pilares da História, Duque de Caxias, v. 4, n. 6, 2006.

OCTAVIO, R. Coração aberto: livro de saudade. 2. ed. Rio de Janeiro: Civilização Brasileira, 1934.

OLIVEIRA JUNIOR, D. L. de. Legislação sobre municípios, comarcas e distritos. Rio de Janeiro: Typ. do Jornal do Comercio, 1926.

PIZARRO E ARAÚJO, J. de S. A. Memória histórica do Rio de Janeiro e das províncias anexas a jurisdição do vice-rei do Estado do Brasil. Rio de Janeiro: Imprensa Régia, 9 v., 1820/22.

RIO DE JANEIRO. Relatório do presidente da província do Rio de Janeiro, o conselheiro Paulino José Soares de Souza na abertura da 1a. sessão da 3a. legislatura da Assembleia Provincial, acompanhado do orçamento da receita e despesa para o ano de 1840 a 1841. 2. ed. Niterói: Tipografia de Amaral e Irmão, 1851.

SILVA, L. Freguesia de Santo Antônio da Jacutinga: um capítulo da história da ocupação da baixada fluminense. Revista UNIABEU, Nilópolis, v. 9, n. 21, 2016.

De Recôncavo da Guanabara a Baixada Fluminense: leitura de um território pela história. Recôncavo: Revista de História da UNIABEU, Nilópolis, v. 3, n. 5, 2013.

SIMOES, M. R. A cidade estilhaçada: reestruturação econômica e emancipações municipais na baixada fluminense. Mesquita: Ed. Entorno, 2007.

Ambiente e sociedade na Baixada Fluminense. Mesquita: Ed. Entorno, 2011.

SOARES, M. T. de S. Nova Iguaçu: absorção de uma célula urbana pelo Grande Rio de Janeiro. Revista Brasileira de Geografia, Rio de Janeiro, v. 2, n. 24, 1962.

\section{Sobre a autora}

Lúcia Helena Pereira da Silva é doutora em História Social pela Pontifícia Universidade Católica de São Paulo (PUC-SP) com pós-doutoramento em Planejamento Urbano e Regional pelo Instituto de Pesquisa e Planejamento Urbano e Regional da Universidade Federal do Rio de Janeiro (IPPUR/UFRJ). Docente permanente do Programa de Pós-Graduação em Desenvolvimento Territorial e Políticas Públicas da Universidade Federal Rural do Rio de Janeiro (PPGDT/UFRRJ), professora do curso de História da UFRRJ/campus Nova Iguaçu. 


\title{
Endereço para correspondência
}

Departamento de História

Avenida Governador Roberto da Silveira s/n, bloco ADM, sala 210, Moquetá/Centro

26020-740 - Nova Iguaçu-RJ, Brasil

\begin{abstract}
Baixada Fluminense as demographicvoid? Population and territory in the old municipality of Iguaçu (1890/1910)

The municipality of Iguaçu occupied what is currently known as the Baixada Fluminense, i.e., it was part of the large municipality which are now Belford Roxo, Duque de Caxias, Japeri, Mesquita, Nilópolis, Nova Iguaçu, Queimados and São João de Meriti, covering a territory representing 35\% of the current metropolitan area of Rio de Janeiro city. The term Baixada Fluminense unifies what emancipations divided, since, at the end of the XIXth Century, the region was a municipality with rural activities and throughout the 20th century, it became an urban periphery. The recurring claim from researchers studying the region, regarding the existence of a demographic void which would have occurred in the late nineteenth century (1890-1910) drew our attention. The aim of this paper is to present the main arguments used in the construction of said image of demographic void and, based on the data obtained in the censuses, to offer some elements which challenge this reading in the manner in which it is stated, since the main thesis is that the region of Baixada (asa whole) became uninhabited, its empty lands becoming disorderly occupied by an urban population fleeing the federal capital and its high prices. This recurrent reading obscures other existing dynamics in the territory beyond the region's own history.
\end{abstract}

Keywords: Baixada Fluminense (Rio de Janeiro lowlands). Population. Occupancy. History.

\section{Resumen}

¿Baixada Fluminense como vacío demográfico? Población y territorio en lo antiguo municipio de Iguaçu (1890/1910)

El municipio de Iguaçu ocupaba la que ahora se llama Baixada Fluminense, es decir que Belford Roxo, Duque de Caxias, Japeri, Mesquita, Nilópolis, Nova Iguaçu, Queimados y São João de Meriti eran parte del grande municipio y abarcaban un territorio que representaba $35 \%$ de la actual región metropolitana de la ciudad de Río de Janeiro. La noción de Baixada Fluminense unifica lo que las emancipaciones fragmentaron, ya que a finales del siglo XIX la región era un municipio con actividades rurales y a lo largo del siglo XX se convirtió en la periferia urbana. Llamó nuestra atención la recurrente declaración de los investigadores que estudian la región sobre la existencia de un vacío demográfico que se habría producido a finales del siglo XIX (1890-1910). El propósito de este trabajo es presentar los principales argumentos utilizados en la construcción de la imagen de vacío demográfico y, con base en los datos obtenidos a partir de los censos de, proporcionar algunos elementos que cuestionan esta lectura que lleva a la afirmación mencionada y cuya tesis principal es que el conjunto de la región de la Baixada se 
despobló y que las tierras fueron ocupadas por una población urbana desordenada que huía de los altos precios de la capital federal. Esta lectura recurrente opaca la existencia de otras dinámicas en el territorio y la propia historia de la región.

Palabras clave: Baixada Fluminense. Población. Ocupación. Historia.

Recebido para publicação em 27/03/2017 Aceito para publicação em 04/08/2017 